\title{
Accuracy Test of Laser Station under Conditions of Air Turbulence**
}

\begin{abstract}
The application of laser stations to industrial metrology indoors is discussed. In this work, only the analysis of the impact of air turbulence to determine the angle of laser wave propagation is discussed, and other meteorological parameters (pressure, humidity) and particles of pollutants (dust, smoke) are ignored. The main aim of this paper was to test the usefulness of a laser station under turbulent air conditions indoors and to estimate the accuracy of this device with values such as angle and distance measurements. Finally, an experimental setup and a method for measuring the turbulence structure coefficient are described. Tests in turbulent air conditions have shown a radical decrease in measurement accuracy. This is demonstrated by both a decrease in power and an increase in the standard deviation of a laser beam, as well as a decrease in the precision of angle and distance measurement. The experimental results show a high correlation between the predicted and measured values.
\end{abstract}

Keywords: laser station, industrial surveying, large-scale metrology, random propagation of laser beam

* UTP University of Science and Technology in Bydgoszcz, Faculty of Civil and Environmental Engineering and Architecture, Department of Geomatics, Geotechnics and Spatial Economy, Bydgoszcz, Poland

** This work was funded by the Ministry of Science and Higher Education of Poland (No. BS-8/2015). The authors would like to express their sincere appreciation to them, and comments from the reviewers and the editor are very appreciated 


\section{Introduction}

Due to the increasing demand for high-accuracy surveying, new surveying instruments have recently appeared on the market. Recent decades have witnessed an increasing interest in Large-Scale/Large-Volume Dimensional Metrology (LSDM). Many fields of application, ranging from construction to shipbuilding and aerospace, have shown increasingly accurate and versatile systems for geometric control. Especially in the last ten years, optical technology has registered a fundamental step forward, alike in terms of metrological performance, versatility, and convenience of use. This diverse stakeholder community is now demanding the dimensional measurement and control of structures and assemblies from several meters up to several kilometers in size as well as to unprecedented levels of accuracy [1-4], often in non-cooperative environments such as large factory spaces, outdoors, or in underground tunnels. Problems that are common at short range, such as surface form and optical interactions with surfaces, are no longer limiting factors for large-range metrology, where issues such as multi-material thermal control, refractive index correction, lack of accurate traceable commercial equipment, and stable facilities for geodetic calibration are more problematic. Obtaining high-accuracy data could, however, be disturbed by irregular and dynamically changing atmospheric conditions such as temperature variation, turbulence, dust, and smoke. These perturbations are difficult to eliminate and have an important impact on the resulting measurements. Determining such changeable meteorological parameters, which are needed to correct the experimental results, is very complex for both outdoor and indoor surveying. Finding a close relationship between the influence of external conditions and measurement accuracy is also a complex issue. In this work, we consider only an analysis of the impact of changes in air temperature to determine the angle of laser wave propagation, ignoring other meteorological parameters (e.g., pressure, humidity) and particles of pollutants (e.g., dust, smoke). The effect of irregular or even regular variations in atmospheric conditions is difficult to eliminate, and reducing their impact on the results of measurement is an intricate problem [5-9]. Due to the fact that conditions in indoor spaces are more stable than in outdoor ones, the use of high-accuracy measurements based on laser technology is more convenient in factory halls. The influence of meteorological parameters on laser optical bending and ways of taking them into account have been widely discussed in such reports as those of Tatarsky [10], Chiba [11], and Strohben [12]. The theoretical considerations have been confirmed by many experiments conducted in research centers all over the world [2, 13-20]. It should be stressed that, in most of these experiments, the laser beam was propagated in the outer layers of the atmosphere. On the other hand, far fewer authors have discussed the problem of laser beam propagation in a closed space $[2,6,8,9,15,16]$. One of the main limitations of the accuracy of optical-length measurements and laser alignment through an uncontrolled atmosphere is the uncertainty in the average refractive coefficient over the optical path due to the absence 
of homogeneity and the turbulence of the atmosphere. Good results can be obtained over short distances at one or more points along the path, but absolute distance measurements with an accuracy of $0.1 \mathrm{ppm}$ or better are difficult to obtain over distances greater than a few dozen meters. The technology based on the latest achievements of laser physics and electronics has allowed for the development of instruments such as laser stations with accuracy as precise as tenths of a millimeter, which were never attainable before [21-24].

The main aim of this paper was to test the usefulness of a Leica TDRA6000 laser station under turbulent air conditions indoors and to estimate the accuracy of this device with values such as the angle and distance measurements declared by the manufacturer. The laser beam was transmitted through turbulent hot air (stimulated by a hot fan) that was in a cylindrical tube in the middle of a 30 meter path of a laser beam.

The test measurements, under conditions of forced turbulence indoors, may not be fully adequate as related to the real factory measurements, but they can provide valuable information on the expected impact of unfavorable atmospheric conditions on accuracy measurement with the use of laser stations in Large-Scale/Large-Volume Dimensional Metrology (LSDM).

\section{The Model}

When a laser beam propagates through a turbulent atmosphere, it experiences random fluctuations in its refractive index. Fluctuations of the refractive index are due to turbulent eddies caused by stochastic variations of temperature. In practice, it is difficult to control the composition of the air in optical instruments sufficiently enough to achieve high accuracy. Under realistic medium conditions, light propagation depends on the concentration of inhomogeneity centers, which change dynamically along the direction of propagation. Laser surveying in an uncontrolled atmosphere requires accurate formulas describing refraction as a function of air perturbation. Due to heterogeneity, the coefficient of refraction, which is the main parameter describing the optical properties of the medium, depends on the position of vector $r$ and can be expressed as [8]:

$$
N(\vec{r})=N_{0}+N_{1}(\vec{r})
$$

where $N_{0}=\langle N(\vec{r})\rangle \cong 1$ is the constant refraction coefficient for a homogeneous medium dependent on temperature, pressure, and humidity in the air, and $N_{1}(\vec{r})$ is the correction accounting for the variation in the refraction coefficient due to turbulence; the angled brackets \langle\rangle indicate the statistical mean (expected value).

Estimation of the uncertainty of laser beam refraction depends on both systematic and random components, as presented in Table 1. 
Table 1. Components of refractive coefficient

\begin{tabular}{||l|l|l||}
\hline \multicolumn{2}{|c||}{ Systematic and Random Refraction } \\
\hline \multicolumn{1}{|c|}{ characteristics } & \multicolumn{2}{|c||}{ atmospheric refraction } \\
\hline Effects & systematic & random \\
\hline Determination & regular refraction & random refraction \\
\hline Reason & $\begin{array}{l}\text { the physical state of the atmosphere } \\
\text { (modeling a large space) }\end{array}$ & $\begin{array}{l}\text { temporal and spatial variation of the } \\
\text { refractive coefficient }\end{array}$ \\
\hline Example & deterministic models of refraction & scintillation \\
\hline
\end{tabular}

Systematic refraction is characterized by regular, slow changes (lasting longer than one minute), and these variations the overlap random fluctuation caused by air turbulence. The theory of the influence of atmospheric turbulence on the propagation of electromagnetic waves has been extensively discussed [10, 12]. Turbulence as a random process is described by stochastic parameters. Taking into account the random changes in velocity (i.e., its value and direction) of each particle of the medium is a complicated issue, and a complete statistical or stochastic analysis is impossible. The existence of temperature gradients in the atmosphere leads to a scattering of the laser beam, and it results in a systematic change in refractive coefficient $N_{0}$ along the path of propagation.

Variation in $N_{0}$ in closed rooms can be connected with the following causes:

- daily changes in temperature caused by the production process,

- seasonal changes of temperature outside industrial buildings,

- heat emitted by various machines used in production.

Due to air convection and turbulence, which often occur at the boundary of two different media (e.g., indoor-outdoor), regular changes in component $N_{0}$ of refractive index $N$ overlap $N_{1}$, which depends on turbulence.

\subsection{The Nature of Turbulence}

The fluctuating part of refractive coefficient $N_{1}(\vec{r})$ can be described with the help of the integral Fourier-Stieltjes transformation, considering it as a random vector function [12]:

$$
N_{1}(\vec{r})=\int d \gamma(\vec{k}) e^{i \vec{k} r}
$$

where $\vec{k}=\left[k_{x}, k_{y}, k_{z}\right]$ is a three-dimensional wave vector and $d \gamma$ is a random spatial amplitude.

Thus, the covariance function of the fluctuations in the refractive coefficient at points at distance $r$ can be written in the form of the following dependence:

$$
B_{n}\left(\vec{r}_{1}+\vec{r}, \vec{r}_{1}\right)=\left\langle N_{1}\left(\vec{r}_{1}+\vec{r}\right) N_{1}\left(\vec{r}_{1}\right)\right\rangle
$$

where the angled \langle\rangle brackets indicate the statistical mean (expected value). 
Putting equation (2) in (3) leads to the spatial form of the following equation [12]:

$$
B_{n}\left(\vec{r}_{1}+\vec{r}, \vec{r}_{1}\right)=\iint e^{i \vec{k}\left(\vec{r}_{1}+\vec{r}\right)-i \vec{k} \vec{r}_{1}}\left\langle d N(\vec{k}) d N^{*}\left(\vec{k}^{\prime}\right)\right\rangle
$$

where ${ }^{*}$ is the value of the complex conjugate.

Assuming that the field is homogenous or in a steady state, it cannot have average characteristics that depend on the location in a field where the average value is calculated. This means that the same result should be obtained by moving the sensors (e.g., temperature) from one location to another. Based on this assumption:

$$
B_{n}\left(\vec{r}_{1}+\vec{r}, \vec{r}_{1}\right)=B_{n}(\vec{r})
$$

Due to the double integral in Formula (4), to meet the requirement for homogeneity, the value contained in the brackets \langle\rangle must satisfy the following condition:

$$
\left\langle d N(\vec{k}) d N^{*}\left(\vec{k}^{\prime}\right)\right\rangle=\delta\left(\vec{k}-\vec{k}^{\prime}\right) \Phi_{N}(\vec{k}) d^{3} \vec{k} d^{3} \vec{k}^{\prime}
$$

where $\delta$ is the three-dimensional Dirac function and $\Phi_{N}(\vec{k})$ is the three-dimensional power spectrum of the refractive coefficient.

Substituting equation (6) into (4) and integrating $k^{\prime}$ (the process of integration can be found in [12]) yields the well-known Fourier transform between the power spectrum density and covariance:

$$
B_{N}(\vec{r})=\int e^{i \vec{k} r} \Phi(\vec{k}) d^{3} \vec{k}
$$

On the other hand, the inverse of (7) will have the following form:

$$
\Phi_{N}(k)=\frac{1}{(2 \pi)^{3}} \int e^{i \vec{k} \vec{r}} B_{N}(\vec{r}) d^{3} \vec{r}
$$

Much work and many experiments have been devoted to function $\Phi_{N}(k)[5,10$, 11, 25, 26]. The most-frequently-used function is the Kolmogorov spectrum, which has the following form:

$$
\Phi_{N}(k)=0,33 C_{N}^{2} k^{-11 / 3}
$$

where $C_{N}^{2}$ is a structural constant refractive coefficient that acts as a measure of its fluctuations and $k=\sqrt{k_{x}^{2}+k_{y}^{2}+k_{z}^{2}}$ in the range of $-\frac{2 \pi}{L_{0}}<k<\frac{2 \pi}{l_{0}}, L_{0}$ is the outer scale turbulence and is described as the greatest distance at which fluctuations in the refractive coefficient are correlated, and this is an internal scale that describes the smallest eddies of turbulence. 
The value of parameter $C_{N}^{2}$ characterizes the various stages of turbulence:

- $C_{N}^{2} \sim 10^{-18} \mathrm{~m}^{-2 / 3}$ - very weak turbulence [27],

$-C_{N}^{2} \sim 10^{-16} \mathrm{~m}^{-2 / 3}$ - weak turbulence [27],

$-C_{N}^{2} \sim 10^{-15} \mathrm{~m}^{-2 / 3}$ - weak turbulence [19],

- $C_{N}^{2} \sim 10^{-14} \mathrm{~m}^{-2 / 3}$ - strong turbulence [27],

$-C_{N}^{2} \sim 10^{-13} \mathrm{~m}^{-2 / 3}$ - very strong turbulence [19].

\subsection{Behavior of a Laser Beam in a Turbulent Atmosphere}

The problem of propagation of an electromagnetic wave in a turbulent atmosphere has been widely discussed [5, 10-12, 17, 18, 20, 26, 28]. To better understand the problem, such an environment has been approximated by assuming that it behaves like a large number of non-identical lenses (eddies) that differ in sizes from $l_{0}$ to $L_{0}$ (Fig. 1).

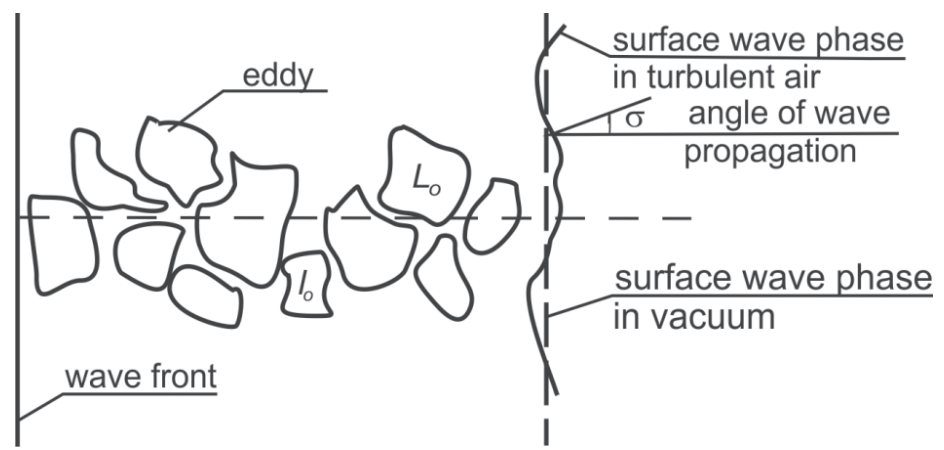

Fig. 1. Propagation of laser beam in turbulent atmosphere

Source: [8]

Concentrating on the situation when the laser beam diameter is smaller than most of the atmospheric heterogeneities (Case B - as can be seen in Figure 2 is justified due to the fact that the typical beam diameter is on the order of millimeters. Also assuming a plane wave front of the laser beam, this condition is fulfilled for the short propagation distance occurring in factory halls.

Spectral analysis for both a plane and spherical wave front is used to determine the fluctuation amplitude, phase, and angle of the laser beam scattering during propagation. The details of this approach can be found in [12]. In order to consider the problem of propagation of a laser beam in a turbulent medium, the following equation must be solved:

$$
\Delta E+k^{2} N_{1}^{2}(r) E=0
$$

where $E$ is the scalar wave function of the propagating laser light intensity, $k=\frac{2 \pi}{\lambda}$ is the wave number ( $\lambda$ is the wavelength of the laser light), $N_{1}(r)$ describes a random local refractive coefficient, and $\Delta$ is the Laplace operator. 

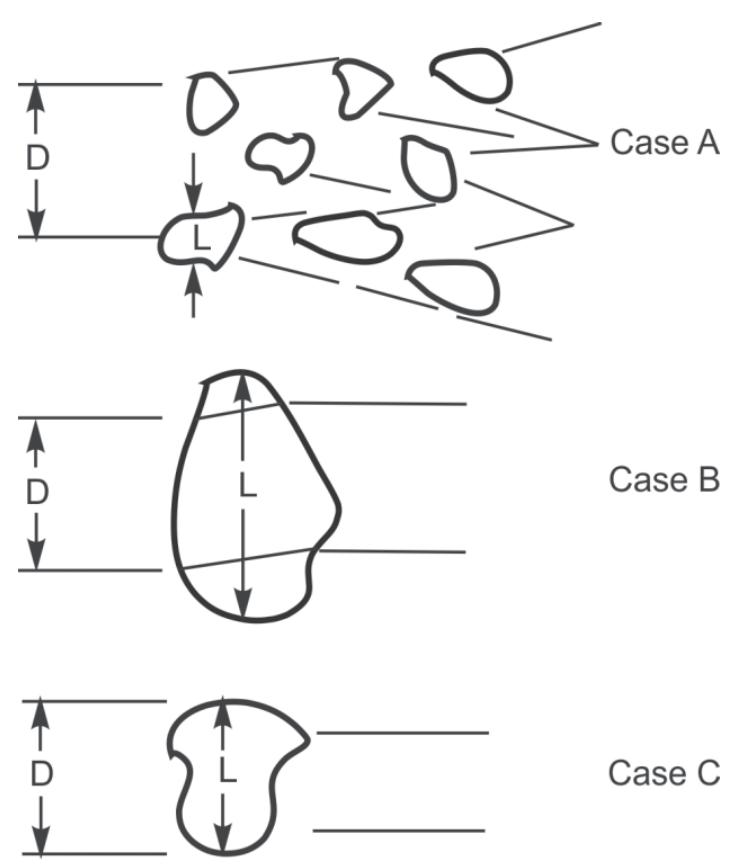

Fig. 2. Action of turbulence components on laser beam ( $D$ is diameter of beam, and $L$ is dimension of turbulent eddy)

Source: [8]

Even if the form of function $N_{1}(r)$ is explicitly given, it is only possible to solve the above equation approximately. The classical approach is a perturbation method, which consists of expansion of $E$ into an infinite series of decreasing elements:

$$
E=E_{0}+E_{1}+E_{2}+\ldots+E_{n}
$$

where $E_{0}$ represents the unperturbed intensity and $E_{1}$ is the first correction connected with dissipation.

The influence of turbulence on the amplitude and phase of the propagating wave that determine the statistical characteristics of fluctuations was considered by [10]. He assumed that the variations in amplitude are described by the log-normal distribution, and the variance of this distribution has the following form:

$$
\sigma_{A}^{2}=\left\langle\ln \frac{A}{A_{0}}\right\rangle^{2}=0.31 C_{N}^{2} k^{7 / 6} L^{11 / 6}
$$

where $L$ is the propagation distance; i.e., the distance between transmitter and receiver. 
In practice, the variance in radiation intensity (which is due to the proportionality of the radiation intensity to the square of the amplitude) is also used as follows:

$$
\sigma_{\ln I}^{2}=4 \sigma_{A}^{2}
$$

\subsection{Angular Deviations of the Laser Beam}

Assuming that the output of the laser beam is focused and has a diameter of $D_{0}$, the equation determining where the radiation will fall to zero as a result of the divergence of diameter $D$ at a distance $L$ will be [29]:

$$
D=2 D_{0}+\frac{2 \lambda}{\pi D_{0}} L
$$

where $\lambda$ - the wavelength.

If diameter $D$ is smaller than the internal $l_{0}$ scale turbulence along the propagation path, the following equation for the angular mean square deviation (variance) of the laser beam at any point in the propagation path can be written as such:

$$
\left\langle\delta^{2}\right\rangle=5.726 C_{N}^{2} l D^{-\frac{1}{3}}
$$

Details on deriving this equation can be found in [8].

However, the total variance of the arrival angle at the end of path $L$ will be:

$$
\left\langle\theta^{2}\right\rangle=\left\langle\delta^{2}\right\rangle \frac{L}{l}
$$

where $\frac{L}{l}$ - the number of elementary segments; therefore:

$$
\left\langle\theta^{2}\right\rangle=5.726 C_{N}^{2} L D^{-\frac{1}{3}}
$$

\section{Test Measurements of the Influence of Air Turbulence on Geodetic Laser Survey}

Recording of the time data was limited to one minute based on the assumption stated in the introduction of this work. This is because systematic refraction, which in the present work has not been studied, occurs after this period. The total number of measurements consisted of eight independent tests for stimulated air turbulence (using a hot fan). 
However, the control measurement was first made in still air.

Angular deviations in a laser beam were measured at the end of the propagation path using a Leica TDRA6000 industrial total station with a Leica 1.5" Red Ring reflector in the "precise" measurement mode. The producer's inspection certificate in accordance with DIN 55350-18-4.2.2 specifies the following accuracy for this device: maximum deviation of distance measurement of $\pm 0.2 \mathrm{~mm}$ (standard deviation of single distance measurement $\sigma=0.1 \mathrm{~mm}$ ) and standard deviation of angle measurement $(\mathrm{Hz}$ and $\mathrm{V}) \sigma=0.15 \mathrm{mgon}$.

In any case, before the test was recorded, laser beam power by means of a sensor was located at the end of the propagation path to determine the intensity of turbulence on the path of the laser beam and their effect on the size of the deviations of the measured angles and distances.

\subsection{Determination of Turbulence Structure Coefficient}

Determination of the coefficient was based on a power fluctuation measurement technique using a Coherent PowerMax-USB/RS model UV/VIS laser beam radiometer with a wavelength ranging from $325 \mathrm{~nm}$ to $1065 \mathrm{~nm}$. A laser beam with wavelength of $650 \mathrm{~nm}$ and a maximum average radiant power of $5 \mathrm{~mW}$ was emitted from a Leica TDRA6000 industrial laser station, which emerged from a telescope objective having an initial diameter of $D_{0}=1 \mathrm{~mm}$ [24]. Then, the laser beam was transmitted through turbulent hot air, which was in a cylindrical tube in the middle of the path of the beam (Fig. 3). The total path length was $30 \mathrm{~m}$.

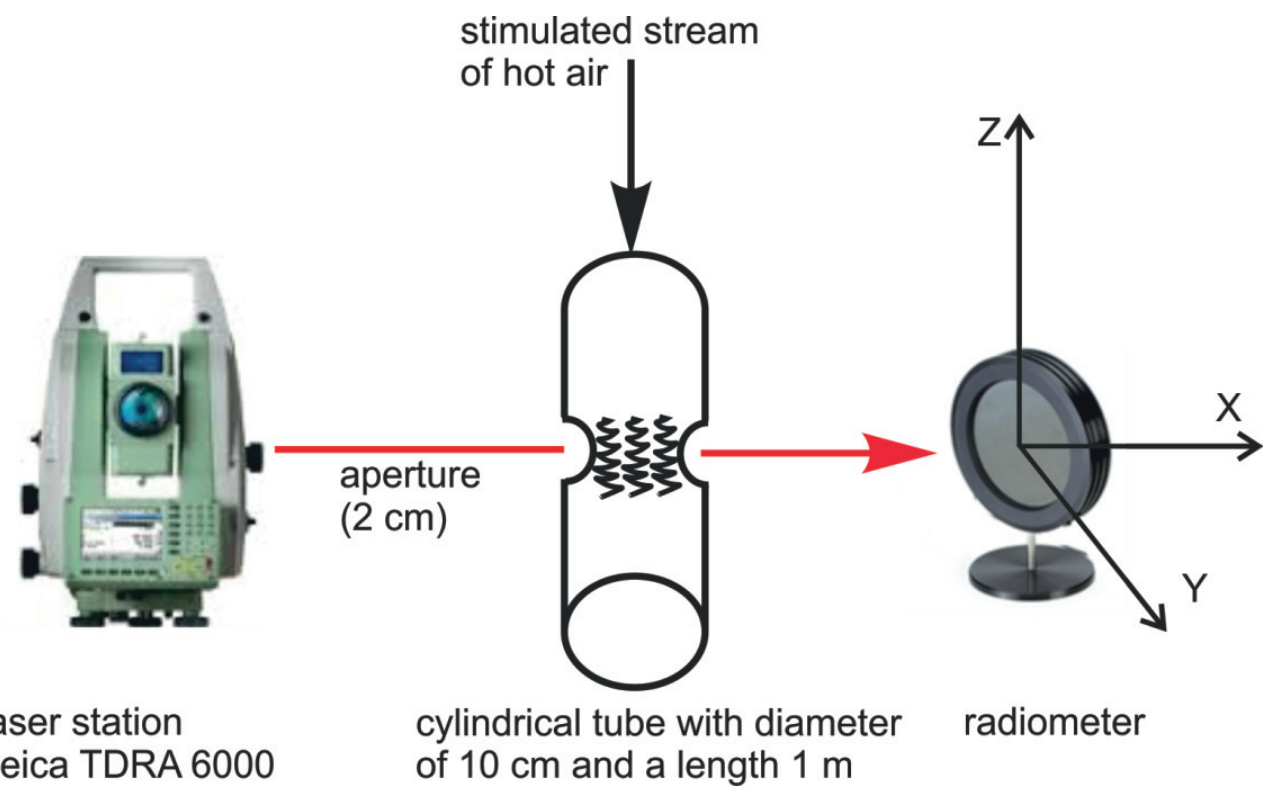

Fig. 3. The experimental setup for measurement of $C_{N}$ 
Examples of power fluctuations recorded by the radiometer under conditions of turbulence and in still air (without a tube and stimulated stream of hot air) within 100 seconds are shown in Figure 4.

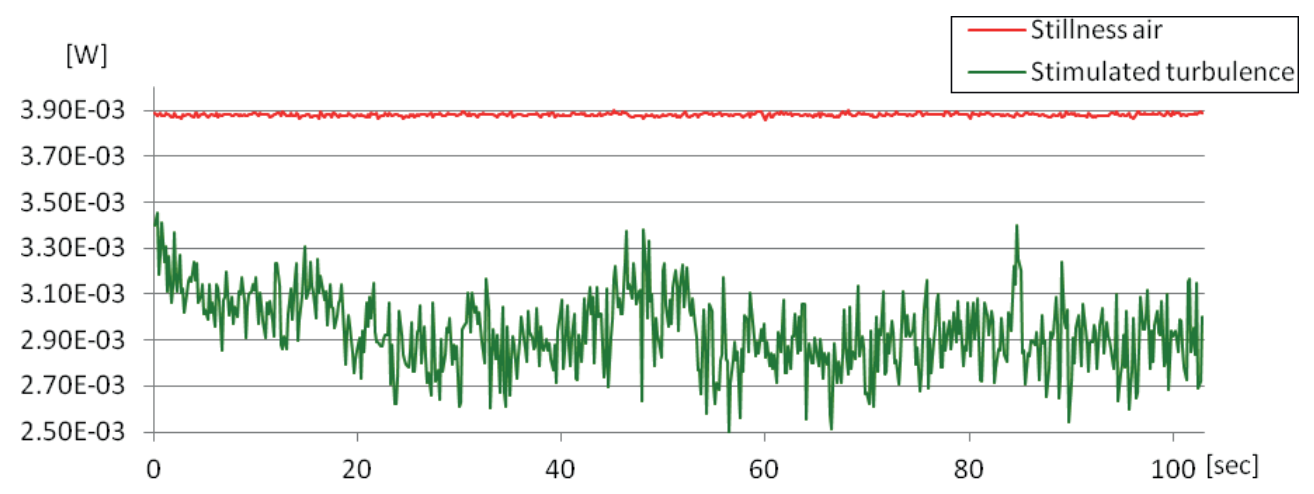

Fig. 4. Fluctuations in the power of the beam recorded by the radiometer in still air and in stimulated turbulence for test no. 2

\subsection{Verification of Angles and Distances Measurements Accuracy under Conditions of Turbulence}

Before performing the proper tests under conditions of forced turbulence, control measurements were performed under stable air conditions. The location of the point was determined by measurement in precision mode on a 1.5" RRR prism at a distance of $30 \mathrm{~m}$ while maintaining the horizontal target axis. At the same time, the values of power for the laser beam, emitted by the laser station, were registered. They were used to calculate the structural $C_{N}$ coefficient, which characterizes the state of the measurement environment using the following formula:

$$
C_{N}=\sqrt{\frac{\delta_{I}^{2}}{1.24 \cdot 2 \pi^{7 / 6} \cdot \lambda^{-7 / 6} \cdot L^{11 / 6}}}
$$

where:

$$
\begin{gathered}
\delta_{I}=\delta_{M} / M-\text { standard deviation of beam intensity, } \\
M-\text { average beam power }[\mathrm{mW}] \\
\delta_{M}-\text { standard deviation of beam power, } \\
\lambda-\text { wavelength laser, } \\
L-\text { beam propagation path. }
\end{gathered}
$$

The results of observations and the $C_{N}$ calculations are presented in Table 2 . 
Table 2. Results of control measurements of angle deviations $\mathrm{dV}, \mathrm{dHz}$, and distance deviation $\mathrm{dD}$ under calm air conditions.

\begin{tabular}{|c|c|c|c|c|}
\hline \multirow{2}{*}{$\begin{array}{c}C_{N} \text { coefficient determined } \\
\text { based on beam power } \\
\text { measurement }\end{array}$} & \multirow{2}{*}{ Measurement no. } & $\mathrm{dHz}$ & $\mathrm{dV}$ & $\mathrm{dD}$ \\
\hline & & [mgon] & [mgon] & [mm] \\
\hline \multirow{23}{*}{$\begin{array}{c}\mathrm{M}=3.88 \mathrm{~mW} \\
\delta_{M}=0.01 \mathrm{~mW} \\
C_{N}=5.487 \mathrm{E}^{-09} \mathrm{~m}^{-1 / 3}\end{array}$} & 1 & 0.09 & -0.22 & -0.08 \\
\hline & 2 & 0.10 & -0.08 & -0.08 \\
\hline & 3 & 0.00 & -0.20 & 0.02 \\
\hline & 4 & 0.07 & -0.15 & 0.02 \\
\hline & 5 & 0.22 & -0.14 & 0.02 \\
\hline & 6 & 0.13 & -0.15 & 0.12 \\
\hline & 7 & 0.05 & -0.15 & 0.02 \\
\hline & 8 & 0.34 & -0.09 & 0.02 \\
\hline & 9 & 0.13 & 0.03 & 0.12 \\
\hline & 10 & 0.19 & -0.10 & 0.12 \\
\hline & 11 & -0.12 & 0.12 & -0.08 \\
\hline & 12 & -0.20 & -0.04 & -0.08 \\
\hline & 13 & -0.10 & 0.17 & -0.08 \\
\hline & 14 & -0.16 & 0.03 & -0.08 \\
\hline & 15 & -0.28 & 0.16 & 0.02 \\
\hline & 16 & -0.07 & 0.22 & -0.08 \\
\hline & 17 & 0.04 & 0.19 & 0.02 \\
\hline & 18 & -0.08 & 0.27 & 0.02 \\
\hline & 19 & -0.20 & 0.03 & 0.02 \\
\hline & 20 & -0.17 & 0.11 & 0.02 \\
\hline & \multicolumn{4}{|c|}{ Standard deviations } \\
\hline & From measurements & 0.16 & 0.15 & 0.07 \\
\hline & Certificated value & \multicolumn{2}{|c|}{0.15} & 0.10 \\
\hline
\end{tabular}

Results of standard deviations of measured angles and distances in the table above are close to the values given in the manufacturer's certificate.

\subsection{Verification \\ of Angles and Distances Measurements Accuracy under Conditions of Forced Turbulence}

The measurements were made thirty times in precision mode (averaging 3 distance readings) aiming at a 1.5" RRR prism using the Automatic Target Recognition function.

The series of readouts was followed by a 15 minute break, after which the measurements were repeated. In total, 8 measurement series were performed, which resulted in 240 observations. 
Before each set of readings of angles and distances, the power of the laser beam emitted by the laser station was recorded. The results of measurements of the laser beam under conditions of forced air turbulence and the calculated $C_{N}$ structural coefficient are reported in Table 3.

Table 3. Structural coefficients calculated on the basis of stimulated turbulence $C_{N}$ for 8 tests

\begin{tabular}{|c|c|c|c|c|}
\hline \multirow{3}{*}{ 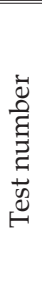 } & \multicolumn{2}{|c|}{$\begin{array}{c}\text { Average beam power with } \\
\text { standard deviation } \\
{[\mathrm{mW}]}\end{array}$} & $\begin{array}{c}\text { Standard deviation of } \\
\text { beam intensity } \\
{[\mathrm{mW}]}\end{array}$ & $\begin{array}{l}\text { Turbulence structural coefficients } \\
\qquad\left[\mathrm{m}^{-1 / 3}\right]\end{array}$ \\
\hline & \multicolumn{2}{|c|}{$M \pm \delta_{M}$} & $\delta_{I}=\frac{\delta_{M}}{M}$ & $C_{N}=\sqrt{\frac{\delta_{I}^{2}}{I^{2}}}$ \\
\hline & $M$ & $\delta_{M}$ & $\delta_{I}$ & $C_{N_{t}}$ \\
\hline 1 & 3.26 & 0.19 & 0.060 & 2.077E-07 \\
\hline 2 & 2.94 & 0.16 & 0.055 & $1.924 \mathrm{E}-07$ \\
\hline 3 & 2.84 & 0.15 & 0.051 & $1.782 \mathrm{E}-07$ \\
\hline 4 & 3.21 & 0.14 & 0.044 & $1.544 \mathrm{E}-07$ \\
\hline 5 & 3.30 & 0.15 & 0.046 & 1.597E-07 \\
\hline 6 & 2.75 & 0.29 & 0.107 & $3.732 \mathrm{E}-07$ \\
\hline 7 & 2.76 & 0.18 & 0.065 & 2.277E-07 \\
\hline 8 & 3.38 & 0.13 & 0.038 & 1.327E-07 \\
\hline
\end{tabular}

However, Table 4 illustrates a comparison of the predicted angular deviations calculated on the basis of formula (17) with the standard deviations $S_{H z}$ and $S_{V}$ determined on the basis of measurements performed with a laser station.

Table 4. The predicted and measured angular deviations of the laser beam

\begin{tabular}{|c|c|c|c|c|c|c|}
\hline \multirow{4}{*}{ Test number } & \multicolumn{2}{|c|}{$\begin{array}{c}\text { Predicted } \\
\text { equation (17) }\end{array}$} & \multicolumn{4}{|c|}{ Calculated from results of tests } \\
\hline & \multirow[b]{2}{*}{$\begin{array}{c}\text { Variances } \\
\left\langle\theta^{2}\right\rangle\end{array}$} & \multirow{2}{*}{$\begin{array}{c}\text { Standard } \\
\text { deviations } \\
\sqrt{\left\langle\theta^{2}\right\rangle}\end{array}$} & \multicolumn{2}{|c|}{ Standard deviations } & \multirow[b]{2}{*}{$\begin{array}{c}\text { Variances } \\
\left\langle\theta^{2}\right\rangle=S_{H z}^{2}+S_{V}^{2}\end{array}$} & \multirow{2}{*}{$\begin{array}{c}\text { Standard } \\
\text { deviations } \\
\sqrt{S_{H z}^{2}+S_{V}^{2}}\end{array}$} \\
\hline & & & $\begin{array}{c}\text { horizontal } \\
\text { plane } S_{H z}\end{array}$ & $\begin{array}{l}\text { vertical } \\
\text { plane } S_{V}\end{array}$ & & \\
\hline & [mgon] & [mgon] & [mgon] & [mgon] & [mgon] & [mgon] \\
\hline 1 & 0.12 & 0.35 & 0.27 & 0.66 & 0.51 & 0.71 \\
\hline 2 & 0.11 & 0.33 & 0.34 & 0.61 & 0.49 & 0.70 \\
\hline 3 & 0.09 & 0.30 & 0.36 & 0.49 & 0.37 & 0.61 \\
\hline 4 & 0.07 & 0.26 & 0.37 & 0.63 & 0.53 & 0.73 \\
\hline 5 & 0.07 & 0.27 & 0.31 & 0.37 & 0.23 & 0.49 \\
\hline 6 & 0.40 & 0.63 & 0.27 & 0.84 & 0.78 & 0.88 \\
\hline 7 & 0.15 & 0.39 & 0.28 & 0.51 & 0.34 & 0.59 \\
\hline 8 & 0.05 & 0.23 & 0.24 & 0.39 & 0.21 & 0.46 \\
\hline
\end{tabular}


The examples illustrating deviations of horizontal and vertical angle measurements from the average value for all readouts are presented in Figure 5 and Figure 6. The measurement deviations of the diagonal distance from the average value are presented in Figure 7.

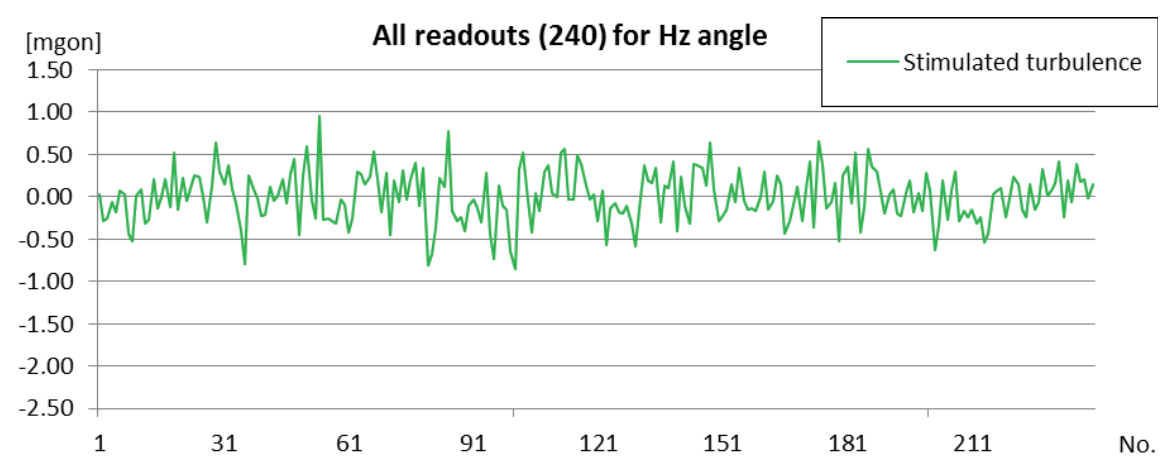

Fig. 5. Deviations of horizontal angle measurements from the average value under stimulated turbulence conditions

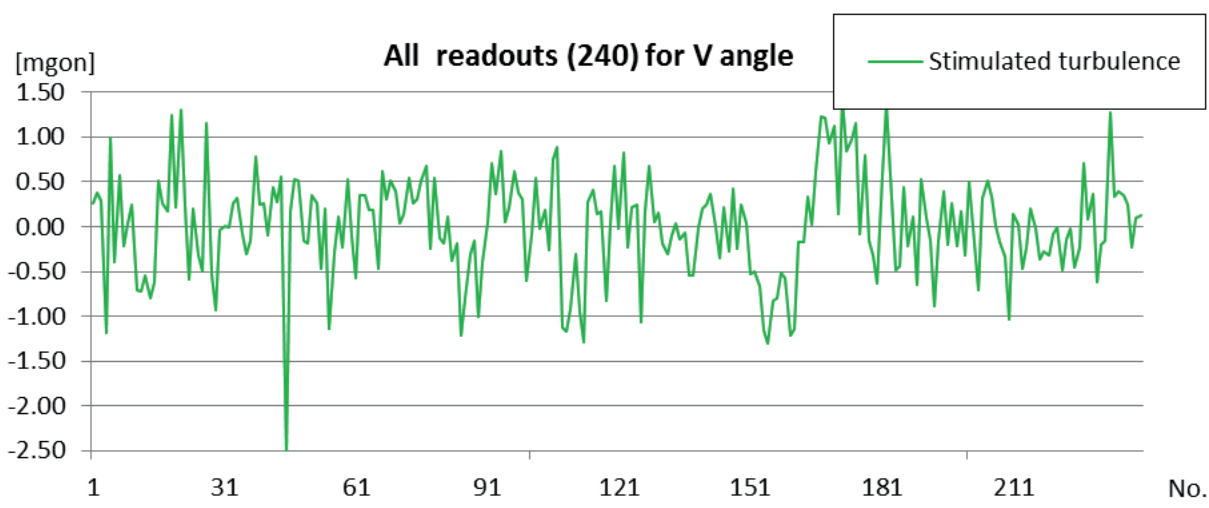

Fig. 6. Deviations of vertical angle measurements from the average value under stimulated turbulence conditions

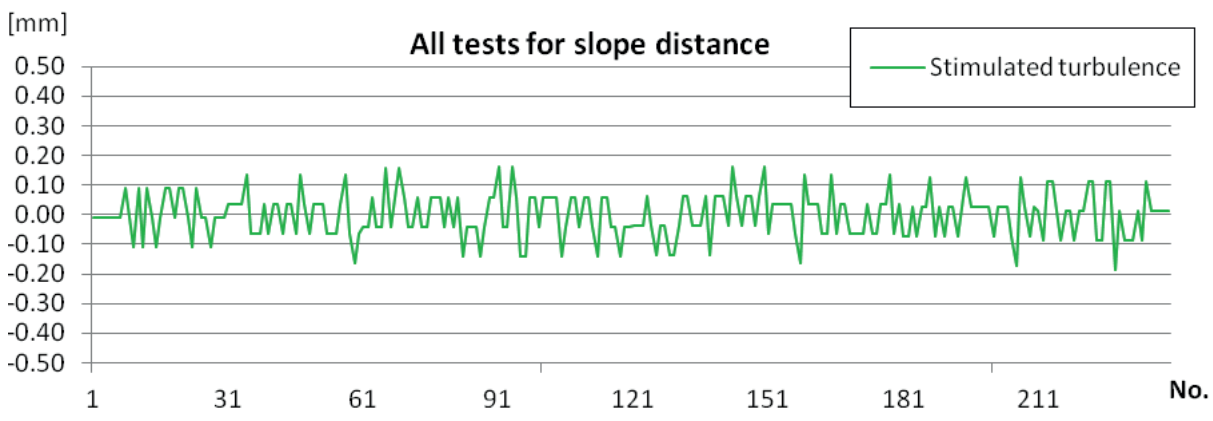

Fig. 7. Deviations of slope distance measurements from the average value under stimulated turbulence conditions 


\section{Conclusions}

The Leica TDRA6000 laser station used for the tests is in accordance with the precision parameters for measurement of angles and distances declared by the manufacturer. Test measurements have shown that standard deviations of results under stable air conditions along the path of propagation of the laser beam have not gone over the values given in the manufacturers' certificate (that is, 0.16 and 0.15 mgon for angles $\mathrm{Hz}$ and $\mathrm{V}$, and $0.07 \mathrm{~mm}$ for the distances).

Tests under forced turbulent air conditions have shown a radical decrease in measurement precision. This is confirmed by both a decrease in power and the increase of the standard deviation of the laser beam, as well as a decrease in precision of the measurement of angles and distances.

Turbulence caused by the flow of hot air along the path of the laser beam have caused an almost two-fold increase in deviations from the average for angle values of \pm 1.0 mgon in the horizontal direction and \pm 1.5 mgon in the vertical direction (Figs. 5, 6). After calculating the components of the $X$ and $Y$ displacement, these values are $\pm 0.5 \mathrm{~mm}$ and $\pm 1.0 \mathrm{~mm}$ under conditions of strong turbulence. There is therefore a significant impact of air turbulence on the measurement accuracy of the laser station. Slope distance measurement accuracy also deteriorated twice, i.e., the standard deviation value increased from $0.07 \mathrm{~mm}$ to $0.12-0.18 \mathrm{~mm}$. However, it is similar to the declared value of the accuracy of $0.1 \mathrm{~mm}$.

The comparison of standard deviations, determined by measuring horizontal and vertical angles with predicted deviations, has confirmed the dependence of the accuracy of measurements on atmospheric environmental conditions.

The values of the standard deviations of the predicted angle under turbulent conditions are included in the range of 0.23 to 0.63 mgon, whereas those calculated from measurements of horizontal $\mathrm{Hz}$ and vertical $\mathrm{V}$ angles were in the range of $0.46-0.88$ mgon. The experimental results show a high correlation $(0.8)$ between predicted and the measured values.

Some differences, occurring between the predicted and the measured values could be the result of insufficient precision of the laser station. In the future, the tests will be repeated with more accurate laser stations, such as a laser tracker under real conditions in a factory where there are sources generating high temperatures (e.g., steel mills, power plants).

In conclusion, we can say that industrial measurements requiring high accuracy, apart from the standard measurements, with a study of the atmospheric environment at the place of measurement (temperature, pressure and humidity) need to be preceded by air turbulence analysis. It is preferable to make preliminary measurements of standard deviation of the laser beam power and to calculate $C_{N}$ index. If its value is $10^{-7}\left(C_{N}^{2} \sim 10^{-14}\right)$ which indicates the presence of strong turbulences [19], it means that the result of measuring with the laser station is affected by an additional error. According to the tests carried out, standard deviation of the measurement 
of $\mathrm{Hz}$ and $\mathrm{V}$ angles can increase more in comparison to precision declared by the producer of the equipment. The surveyor must decide then whether further measurements under such conditions will make it possible to achieve required precision. Alternatively the problem of air turbulence within measurement direction can be solved by using such measurement equipment which performs measurements with multiple sampling. On the basis of partial results it calculates average standard deviation of single observation and it stops measurements if limit values have been exceeded. Such solutions are currently used in laser trackers. These options specify a position tolerance when taking stationary measurements. When a point is probed using a stationary measurement, several readings are made within the specified time period and a deviation is calculated. If the deviation exceeds the position tolerance value, the point is refused. The deviation is displayed as the RMS value (Root Mean Square) in the Digital Readout window.

For the accurate total stations which are not equipped with such sampling techniques it is necessary to check the strength of atmospheric turbulence. The decision to include the influence of turbulence on measurements precision is determined by the result of measurement of standard deviation of the laser beam power and on this basis calculate the turbulence coefficient $C_{N}$.

\section{References}

[1] Franceschini F.: Large-Scale Dimensional Metrology (LSDM): from tapes and theodolites to multi-sensor systems. International Journal of Precise Engineering and Manufacturing, vol. 15, issue 8, 2014, pp. 1739-1758.

[2] Gulich D., Funes G., Zunino L., Perez D.G., Garavaglia M.: Angle-of-arrival variance's dependence on the aperture size for indoor convective turbulence. Optics Communications, vol. 277, no. 2, 2007, pp. 241-246.

[3] Galetto M, Mastrogiacomo L, Pralio B.: An innovative indoor coordinate measuring system for large-scale metrology based on a distributed IR sensor network. [in:] Proceedings of the ASME 2009 International Manufacturing Science and Engineering Conference (MSEC2009): October 4-7, 2009, West Lafayette, Indiana, USA, 2009, pp. 1-9.

[4] Peggs G.N., Maropoulos P.G., Hughes E.B., Forbes A.B., Robson S., Ziebart M., Muralikrishnan B.: Recent developments in large-scale dimensional metrology. [in:] Proceedings of the Institution of Mechanical Engineers, Part B: Journal of Engineering Manufacture, vol. 223, issue 6, 2009, pp. 571-595.

[5] Kwiecien J.: The influence of temperature factors on the results of remote and continuous displacement measurements using laser in closed rooms. [in:] Geodetic Measurements of Deformations $4^{\text {th }}$. Proceedings of International Symposium FIG PC/85, Katowice 9-16 June 1985, pp. 244-253.

[6] Kwiecień J.: De invloed van turbulentie op een laserstraal in een gesloten ruimte. NGT Geodesia, no. 11, 1985, pp. 12-18. 
[7] Kwiecień J.: Determination of heights by laser alignment. Survey Rewiev, vol. 28, issue 222, 1986, pp. 411-418.

[8] Kwiecień J.: Automatyczne laserowe tyczenie prostej odniesienia w pomieszczeniach fabrycznych ze szczególnym uwzględnieniem turbulencji atmosferycznej. Rozprawy nr 32, Akademia Techniczno-Rolnicza w Bydgoszczy 1989.

[9] Kwiecień J., Żak M.: Refraction free method of Laser Alignment. [in:] $2^{\text {nd }}$ International Workshop on Accelerator Alignment (IWAA 90) 10-12 Sep 1990. Hamburg, Germany, 1990, pp. 305-313.

[10] Tatarsky V.I.: The effects of the turbulent atmosphere on wave propagation. Israel Program for Scientific Translations, Springfield Company, 1971.

[11] Chiba T.: Spot dancing of the laser beam propagated through the turbulent atmosphere. Applied Optics, vol. 10, no. 11, 1971, pp. 2456-2461.

[12] Strohbehn J.: Laser beam propagation in the atmosphere. Springer Verlag, New York 1978.

[13] Alim, Ngo Nyobe E., Pemha E.: Theoretical prediction and experimental validation of the angle-of-arrival probability density of a laser beam in a strong plane-flame turbulence. Optics Communications, vol. 283, no. 9, 2010, pp. 1859-1864.

[14] Frehlich R.: 2000. Simulation of laser propagation in a turbulent atmosphere. Applied Optics, vol. 39, no. 3, pp. 393-397.

[15] Pemha E., Ngo Nyobe E.: Genetic algorithm approach and experimental confirmation of a laser-based diagnostic technique for the local thermal turbulence in a hot wind tunnel jet. Progress in Electromagnetics Research B, vol. 28, 2011, pp. 325-350.

[16] Pemha E.: Correlations of Deflection Angles of a Laser Beam in a Hot Turbulent Jet of Air: Theoretical Determination and Experimental Measurement of the Structure Coefficient of Refractive Index Fluctuations. Progress in Electromagnetics Research B, vol. 42, 2012, pp. 425-453.

[17] Weiss A.: Determination of thermal stratification and turbulence of the atmospheric surface layer over types of terrain by optical scintillometry. Swiss Federal Institute of Technology, Zurich 2002 [Diss. ETH No. 14514, Ph.D. Thesis].

[18] Wei H., Ma Q.: Log-amplitude variance of laser beam propagation on the slant path through the turbulent atmosphere. Progress in Electromagnetic Research, vol. 108, 2010, pp. 277-291.

[19] Dordová L., Wilfert O.: Laser Beam Attenuation Determined by the Method of Available Optical Power in Turbulent Atmosphere. Journal of Telecommunication and Information Technology, vol. 2, 2009, pp. 53-57.

[20] Zunino L., Gulich D., Funes G., Pérez D.: Turbulence-induced persistence in laser beam wandering. Optics Letters, vol. 40, issue 13, pp. 3145-3148.

[21] Zobrist T., Burge J.H., Peng S., Chunyu Z.: Use of a commercial laser tracker for optical alignment. [in:] Optical System Alignment and Tolerancing: 26-27 August 2007, San Diego, California, USA, Proceedings of SPIE 6676, SPIE, 2007. 
[22] API Automated Precision. [on-line:] http://www.apisensor.com [access: 12.08.2015].

[23] Faro. [on-line:] http://www.faro.com [access: 12.08.2015].

[24] Leica Geosystems. [on-line:] http://leica-geosystems.com/[access:12.08.2015].

[25] Kwiecien J.: The influence of atmospheric conditions on the results of laser geodetic survey. Rendiconti del Seminario della Facolta di Scienze dell'Univerisita di Cagliari, Italy 1982.

[26] Dinther D. van, Hartogensis O.K., Moene A.F.: Crosswind from a Single-Aperture Scintillometer Using Spectral Techniques. Journal of Atmospheric and Oceanic Technology, vol. 30, 2013, pp. 3-21.

[27] Davis J.I.: Consideration of Atmospheric Turbulence in Laser Systems Design. Applied Optics, vol. 5, no. 1, 1966, pp. 139-147.

[28] Kolmogorow A.A.: Dissipation of energy in locally isotropic turbulence. Akademic-Verlag, Berlin 1978.

[29] Holejko K.: Precyzyjne elektroniczne pomiary odległości i kątów. Wydawnictwa Naukowo-Techniczne, Warszawa 1981.

\section{Badanie dokładności stacji laserowej w warunkach turbulencji powietrza}

Streszczenie: W artykule przedstawiono zastosowanie stacji laserowych do metrologii przemysłowej $\mathrm{w}$ pomieszczeniach zamkniętych. W pracy poddano analizie wpływ turbulencji powietrza na zmianę kąta propagacji fali laserowej. W badaniach nie uwzględniono zmian ciśnienia atmosferycznego, wilgotności oraz występowania oraz występowaania cząstek zanieczyszczeń powietrza (pyłu, dymu). Głównym celem tego opracowania było zbadanie przydatności stacji laserowej w warunkach turbulentnego powietrza wewnątrz budynku oraz oszacowanie dokładności tego urządzenia przy pomiarach kątów i odległości. Opisano również aparaturę eksperymentalną i metodę pomiaru współczynnika struktury turbulencji. Testy $\mathrm{w}$ turbulentnych warunkach powietrza wykazały radykalny spadek dokładności pomiaru. Wynika to zarówno ze zmniejszenia mocy, jak i wzrostu standardowego odchylenia kąta propagacji wiązki lasera, a także zmniejszenia dokładności pomiaru kąta i odległości. Wyniki eksperymentalne potwierdziły wysoką korelację między wartościami przewidywanymi a zmierzonymi.

Słowa

kluczowe: stacja laserowa, pomiary przemysłowe, metrologia, propagacja wiązki laserowej 